\title{
CONSUMERS' WILLINGNESS TO PAY FOR ORGANIC PRODUCTS: A CASE FROM KATHMANDU VALLEY
}

Kamal P. Aryal (MSC )*1, Pashupati Chaudhary (PhD)2, Sangita Pandit (BSC)3 and Govinda Sharma $(\mathrm{MSC})^{4}$

\begin{abstract}
This paper presents the consumers' willingness to pay a price premium for organic products in Kathmandu Valley. The Nepal Permaculture Group surveyed 180 consumers using semi-structured questionnaires to examine peoples' perception about organic products and assess their willingness to pay for such products. The study revealed that all respondents are willing to pay price premium, but the level of acceptability varied considerably. A total of $58 \%$ of the consumers are willing to pay 6- $20 \%$ price premium, whereas $13 \%$ are willing to pay up to $50 \%$ premium. The average premium was estimated about $30 \%$. About $39 \%$ of the respondents feel the extra cost for organic products is reasonable, while $27 \%$ considered it too high. The survey also suggested that the consumption of organic products is increasing; however, product development and innovations in certification, processing, labeling and packaging are needed to further stimulate demand.
\end{abstract}

Key words: certification, consumer perception, organic products, price premium, processing, willingness to pay

\section{INTRODUCTION}

The role of organic agriculture in providing food and income is now gaining wider recognition (Van Elzakker et al 2007). The market of organic products is growing as the number of people willing to eat organic food and pay premium price is increasing. The future of organic agriculture will, to a large extent, also depend on consumer demand and their motive for paying extra price for organically grown food. Thus, a consumer-oriented approach to understanding the market for organic products is important for pursuing better management of organic farming. However, this is a complex process, which is determined by factors such as quality production, certification, infrastructure and market environment and policies (Aryal, 2008). It is also important to understand consumer decision-making regarding organically produced foods and seek strategies about how consumption can be promoted.

Production and marketing strategies are determined by consumer beliefs, attitudes, responses to organically grown products and the willingness to pay a premium price. Because organic products are credence goods, consumers may not know whether a product is produced using organic or conventional methods unless they are told so (Giannakas, 2002). Thus, awareness and knowledge about organically produced foods are critical in the consumer purchase decisions. Krissoff (1998) reported that consumers purchase organic products because of a perception that such products are safer, healthier and more environmentally friendly than conventionally produced alternatives. Human health, food safety along with several other product characteristics such as nutritive value, taste, freshness, appearance, and other sensory characteristics influence consumer preferences (Makatouni, 2002, Bonti-Ankomah and Yiridoe, 2006).

\footnotetext{
${ }^{1}$ Nepal Permaculture Group, GPO box 8132, Tel. No.+977-1-4252597, Fax no. +977-1-4419284, aryal.kamal@gmail.com

2 PhD Scholar, University of Massachusetts Boston, 100 Morrissey Blvd., Boston MA 02125, USA, Pashupati.chaudahry@umb.edu

${ }^{3}$ Research Assistant, Nepal Agriculture Research Council, sangitaiaas@yahoo.com

${ }^{4}$ Nepal permaculture Group, govindasharmma@yahoo.co.uk
} 
In Nepal, consumption of organic foods hitherto constitutes only few percent of total food consumption of the country (Aryal, 2008 and Ranabhat, 2008). Nevertheless, the demand for organic products has increased during the recent times, especially in the Kathmandu Valley, Chitwan and Pokhara. The number of market outlets for organic products has also increased. Traders have reported that consumers are willing to pay price premiums. For further betterment of management, a more detailed study in understanding the perception of people about organic foods is required. It is also important to understand how willing people are to pay more price for organic products. A survey was initiated by The Nepal Permaculture Group (NPG) to understand consumers' perceptions on the organic products and their willingness to pay price premium. The survey was conducted in the Kathmandu valley.

\section{OBJECTIVE}

The aim of this study is to shed light on consumers' perceptions about organic products and their willingness to pay for such products. More specifically, the objectives of the study are:

- To increase understanding of consumers' awareness, attitude and perceptions towards organic products,

- To assess consumers' willingness to pay (WTP) for organic products,

- To identify factors influencing consumers' willingness to pay (WTP) for organic products, and

- To identify the major organic products and market outlets in the valley dealing with organic products.

\section{THEORETICAL FRAMEWORK}

In general, the willingness to pay a price premium decreases as the price premium increases, consistent with the law of demand. In consumer behavior theory, consumers make their own decisions to balance the marginal health utility and marginal price of one unit of quality-food products.

In this research, a simple framework was used (Fig.1) to analyze consumer behavior towards food products, which includes the willingness to pay a price premium. Consumers decide whether to buy a product or not based on three main aspects: Knowledge, Attitude and Intention. Knowledge about products and their benefits influences their willingness to pay for the products. Knowledge of people is affected by type and quality of information made available to consumers. Advertisement, quality packaging, labeling and certification play pivotal role in knowledge enrichment. Once a consumer is ready to buy, the next step is to see how much he or she is willing to pay for the product. Purchase behavior reflects the real WTP and the consumer gains positive or negative experiences which will reversely affect consumers' WTP in future. Knowledge and awareness have respectively direct and indirect effects on attitudes toward consumer to choose the products, and the willingness to pay a price premium, so they are important factors determining the demand. Thus, awareness and knowledge about organically produced foods are critical in the consumer willingness to pay more for the product.

Similarly, the framework presented in Figure 2 reflects the factors affecting consumers' attitude and willingness to purchase. Consumers' willingness to purchase is affected by exogenous factors like processing, packaging, certification and labeling and consumers' 
knowledge and awareness about the products. If an individual cannot clearly differentiate between two alternative products, a price premium on the organic product can confuse and/or affect the individual's purchasing decision. Consumers' education, occupation, household size along with product attributes affects their attitude and preference to buy the products. These factors further depend on consumers' household income and product price to make a decision for purchase.

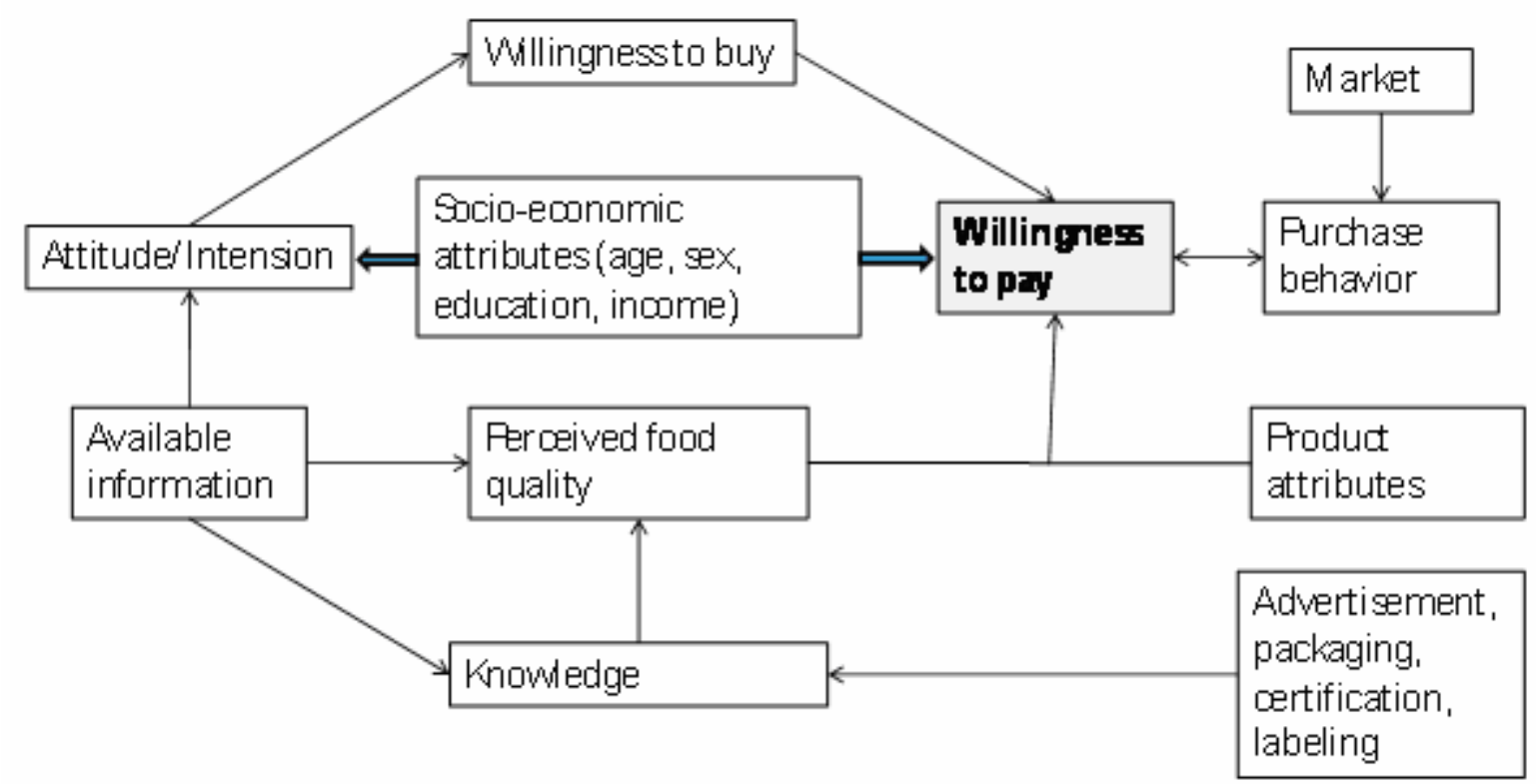

Figure 1: Framework reflecting consumer behavior towards food products (adopted from Millock (2002) and Bonti-Ankomah and Yiridoe (2006)

\section{METHODOLOGY}

The data were collected during October and November 2008 from a stratified random sample of 180 consumers in Kathmandu valley. In general, sample size depends on the characteristics of the population, the sampling techniques and selection of variables and statistical confidence levels. A general rule is that 30 individuals are sufficient for individual survey although homogenous populations require smaller samples than heterogeneous populations (Salkind 2003).

The process of individual selection was made in two stages; first, Stratified proportionate random sampling was done for identifying the consumers category within the Kathmandu valley because the study population is heterogeneous in terms of their socio-economic status. Six types of consumers with different professions were identified, based on the assumption that their profession affects their attitude, awareness, preference and willingness to pay. Our quick observation and rapid appraisal on identifying type of organic food consumers showed that there are, in general, six types of organic food consumers namely, teachers, NGO/INGOs workers, health professionals, government officials, general public buying vegetables at the Kalimati Fruit and Vegetable Wholesale Market and businessmen. Secondly, 30 individuals were randomly selected from each category for the individual interview.

A total of seven traders from Organic Village, Organic World and Fair Future (OWF), Prakriti Ghar, Appropriate Alternative Asia (AAA), Café U, Caroline Restaurant and Mikes breakfast including staff working in the outlets, were interviewed to know more about the different products available in the outlets and their current marketing status in the valley. 
The purposive sampling was done to identify the traders on the basis that they are the leading supplier of organic products in the valley.

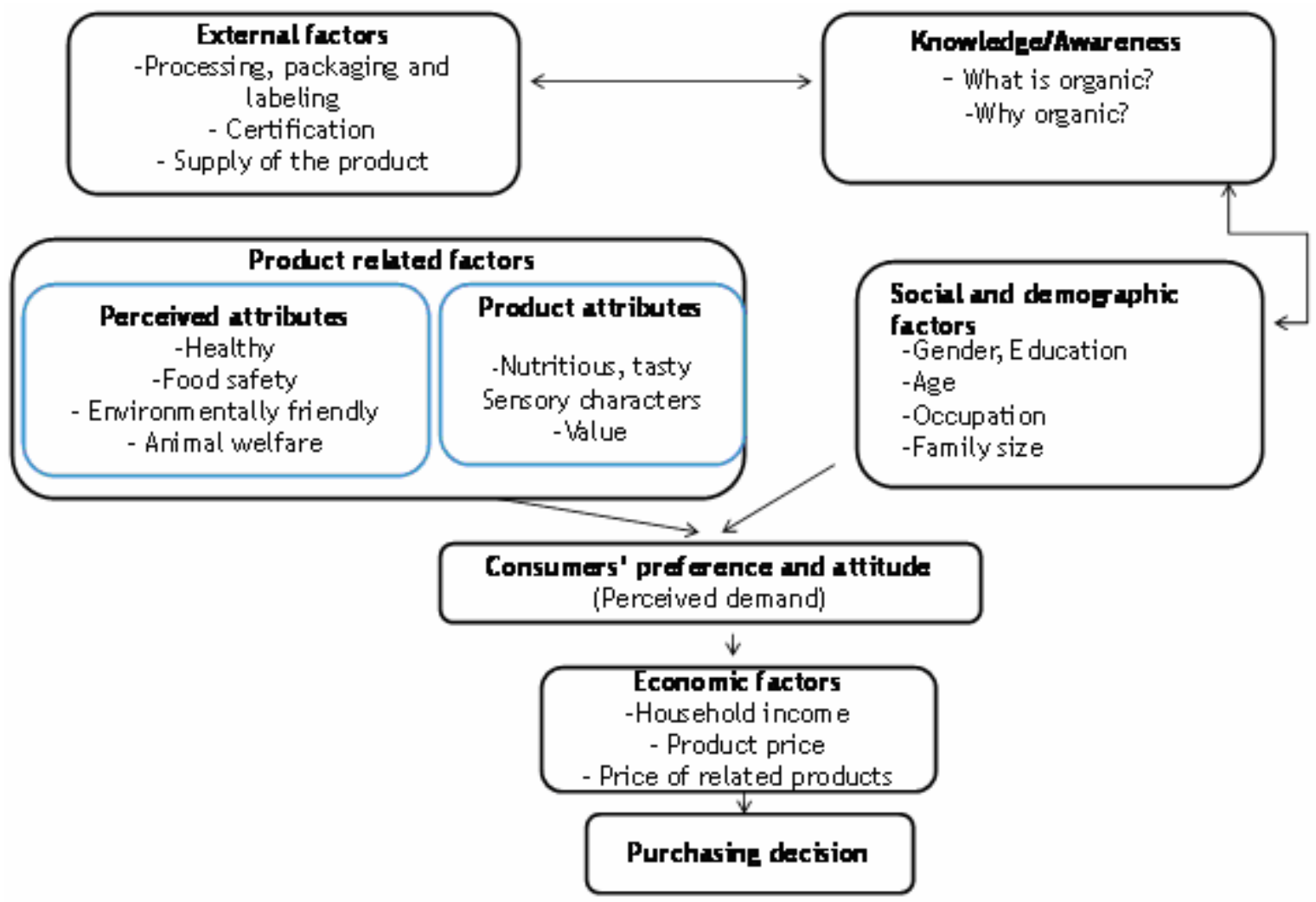

Figure 2: Framework of factors affecting organic consumers' attitudes and willingness to purchase, adopted and modified from Bonti-Ankomah and Yiridoe (2006).

The questionnaire was developed through pre-testing of each question via personal interviews with the consumers. The interviewed individuals were asked to state their interpretations of a series of suggested questions.

Data enumerators were hired for the survey. The enumerators were oriented about the questionnaire and data collection technique before they were deployed in the field. The collected data were then analyzed both quantitatively and qualitatively.

\section{RESULTS AND DISCUSSION}

\section{MAJOR PRODUCTS MARKETED AS ORGANIC IN KATHMANDU VALLEY}

The diverse ranges of organic products are marketed in Kathmandu Valley. Mr. Samir Newa, Manager of Organic village reported that they are currently selling about 40 different vegetables, 8 fruits varieties, 6 rice varieties, 6 varieties of beans and pulses and 6 items of milk products. Similarly, Juice of seabuckthorn and jam from lapsi are other highly demanded organic products available in the outlets. The major products marketed in the valley are vegetables followed by cereals and pulses. Mostly the vegetables are seasonal and the highly demanded are lettuce and tomato for salad purpose. Similarly, spinach, turnip, carrot, cabbage, leek are the major vegetables currently available as organic. In fruits, avocado, kiwi and banana are the major products available in the outlets. In rice, red rice is the most demanded product not only in country but also exported in Europe and South Africa. Mr. Newa reported that, he is selling on an average of NRs. 30,000 per day from his three outlets located in Baluwatar, Bakhundole and 
Kupandole. Similarly, he has just started exporting some of the organic products like red rice, white and turtle beans, garlic and zinger powder in South Africa and earning foreign currency. According to Mr. Newa, he is able to earn around US\$ 15,000 in just four months of his debut. Similarly, Mr. Prasad Chhetri, Managing Director of Organic World and Fair Future (OWF), recently established organic market outlets in the valley, mentioned that the demand for organic products is increasing in recent days. The major products available are seasonal vegetables like cauliflower, cabbage, potato, green leafy vegetables (high demand). Six varieties of rice, five different varieties of beans are the products available in both market outlets (Jhonche and Basundhara). Rhododendron juice, orange juice and seabuckthorn juice are the popular products of their outlets. Likewise, honey, coffee, sliced dry apple, zinger and garlic (both powder and fresh) are some of the better selling products. He further reported that they are selling organic products on an average of NRs 3 lakhs per month.

\section{CONSUMER KNOWLEDGE ABOUT ORGANIC PRODUCTS}

The study found that a majority $(90 \%)$ of the surveyed consumers had heard about the organic products. However, they are often not sure which products are organic and which are not. This finding is in concordance with that of Bhatta et al. (2008), who report that about $92 \%$ of the consumers knew about organic agriculture.

The perception and understanding about organic products varies depending on the type of consumer. Business people perceived that the product will be organic if producer did not use chemical pesticides. Government officials and NGO/INGO people perceived that products are organic if there is a total absence of chemicals (fertilizers and pesticides), but there could be a use of Farm Yard Manure (FYM) and compost. Hill and Lynchehaun (2002) also reported similar findings on their study. The study found that organically produced foods are those which are naturally grown and produced by using local resources. Similarly, Teachers perceived that the product should be free from pesticide use. While the health professionals and consumers buying at vegetable market at Kalimati mentioned that organic product should be free from chemical use and other external contamination.

The results show that the knowledge and awareness level among the surveyed consumers are fairly good but not adequate. Hence, awareness raising programmes among existing and new consumers on organic products could be an effective mechanism for the promotion of organic products in future. Awareness can be increased through campaign, demonstration, public gatherings, etc. The extension services as well as government-led institutional supports in promoting organic farming are very limited (Pokhrel and Pant, 2008). Product certification is also not properly done by the government agencies. Therefore, institutional support from the government is required to develop certification process as well as branding of the products.

\section{CONSUMERS’ PREFERENCE ON ORGANIC PRODUCTS}

We examined whether people have any preferences on crop products that are organically grown. About $42 \%$ of the respondents reported that vegetables are their first choice followed by pulses $(28 \%)$ and fruit $(20 \%)$. Only $10 \%$ consumers preferred rice as their first choice. The main reasons given for their preferences are health (75\%), taste and palatability (18\%) and good appearance and freshness $(7 \%)$. The reason of health was most important for the respondents from the (I)/NGOs and health sector, followed by the government officials and teachers. It could be because educated people are more conscious about health problems caused by chemical fertilizer and pesticides. 
Similar findings are reported in past by some other researchers. Bourn and Prescott (2002) reported that besides health, food safety and environmental considerations, several other product characteristics such as nutritive value, taste, freshness, appearance, color and other sensory characteristics influence consumer preferences. Bhatta et al. (2008) found that the majority (53\%) prefer organic vegetables because of health and safety reasons, and $12 \%$ for their better taste.

\section{CONSUMERS’ WILLINGNESS TO PAY FOR ORGANIC PRODUCT}

The result showed that in case of product availability, all the consumers are willing to pay higher prices for organic products. The price premium is ranging from $5 \%-50 \%$ depending upon the products and consumers' willingness to buy. The current average premium is about $30 \%$. The consumers survey revealed that $28 \%$ of the interviewed consumers $(\mathrm{N}=180)$ are willing to pay up to $20 \%$ price premium compared with non-organic. Similarly, $13 \%$ of the consumers like to pay between $20-50 \%$ price premiums. In comparison, $59 \%$ of consumers are not willing to pay more than $10 \%$ price premium for any organic products (Figure 3). Similar study by Asadi et al. (2009) in Iran reported that majority of the consumers are not willing to pay a price premium higher than $20 \%$. The similar study by Millock (2002) in Denmark reprotedthat, 35\% of the consumers are willing to pay more for any type of organic products compared to $18 \%$ of consumers who are not willing to pay for all kind of products. In this case, organic products also depends with the consumers preference which product to buy or not. Menon (2008) on his paper organic agriculture and market potential mentioned that the organic product are gaining price premium from $5 \%$ to as high as $60 \%$ in some products.

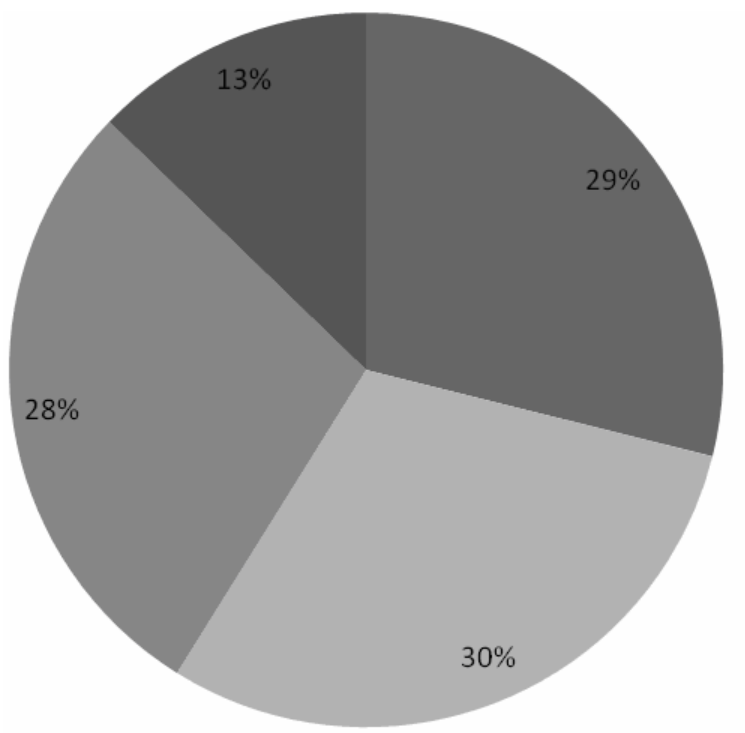

The study signaled that among the surveyed consumers category of professional, government officials and those working in NGO/INGOs are willing to pay more (Figure 4). The Government officials' upto $5 \%$ premium willingness to pay is 6-10\% premium almost double price premium of those who $11-20 \%$ premium are paying more than $10 \%$ premium (20 out of 30 $>21 \%$ premium consumers) than teachers (10 out of 30$)$. Even if the price goes higher consumers are willing to buy these products considering less risk to their health. Sandalidon et.al (2002) has mentioned that health is the main reason for purchase of organic, followed by quality characteristic such as taste, colour and flavor. Even if the part these "safe products" play in the food consumption budget is still small, they are considered a market niche of great potential growth. The demand for such products in Kathmandu valley is increasingly growing (Aryal 2008); however, for further promotion of such products, the lack of information available to consumers; cheaper prices over those of conventional foods; and the limited and erratic domestic supply are some of the factors to be taken into consideration in future. Besides, many consumers do not trust the products which do not have well labeled and certified by established certified agencies (Ranabhat, 2008; Rodriguez et. al, 2007). 
Figure 3: Consumers' willingness to pay premium price for organic products $(N=180)$

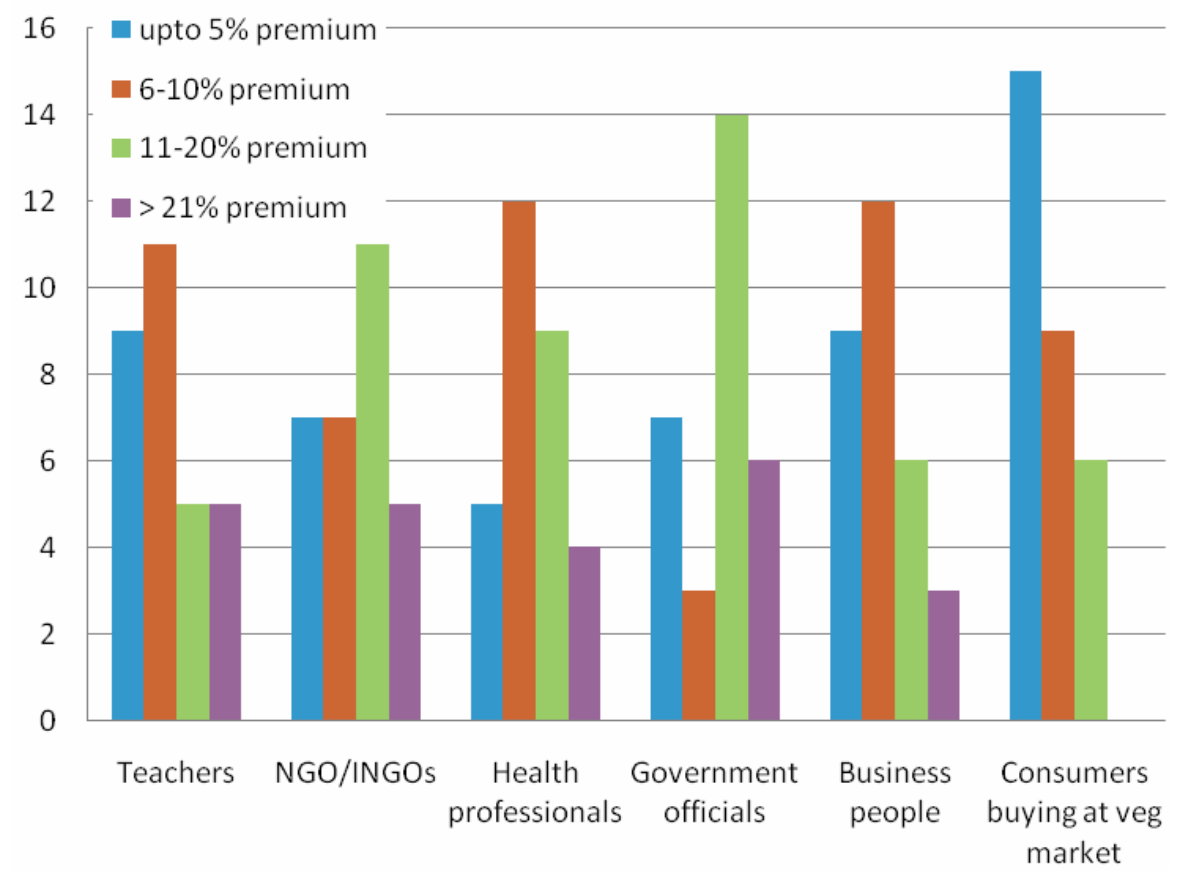

Figure 4: Consumers' willingness to pay premium price for organic products by different professions $(\mathrm{N}=30$ in each category)

\section{CONSUMERS' \\ PERCEPTION ABOUT THE PRICE}

In general, consumers' perceptions about the current price of organic product are very positive. Nearly $40 \%$ of the consumers reported that the price of organic products compared with conventional one is reasonable. In the recent days, organic products compete with conventional alternatives in the market. Consumers feel that the price depends on the market and the specific goods. Majority of the consumers reported that fresh vegetables specially the leafy one have higher price compared with other. About $27 \%$ consumers (49 individual out of 180 ) perceived that the average price of organic product is higher compared to conventional ones (Figure 5). The comparison with inorganic product by the consumers might be the main reason for their perception that the organic products expensive. The study findings further showed that despite of having higher price compared to conventional alternatives, many consumers continue to buy organic products. This is further supported by the study findings like consumers who usually buy organic food were more concerned about food safety than price (Shakya, 2005; Aguirre, 2001).

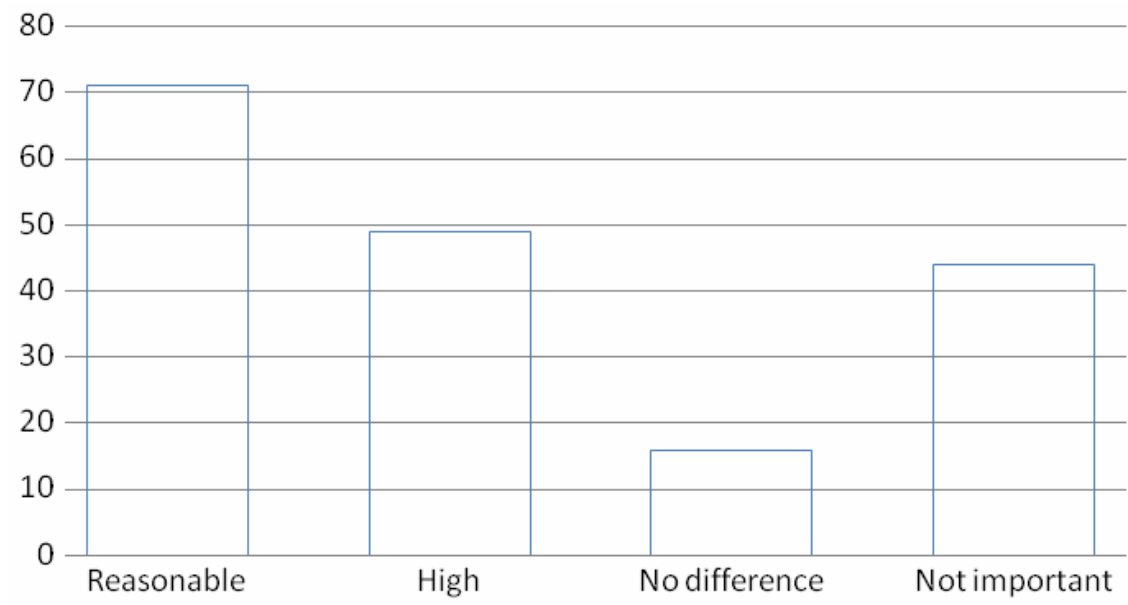

Figure 5: General perception of consumers about the price of organic products $(\mathrm{N}=180)$

On the other hand, the segregated data showed that those who used to go for Kalimati think that organic products are higher in price compared with inorganic. Fifty percent

of the vegetable buyers at the Kalimati Fruit and Vegetable Wholesale Market perceived that the price is higher as against $16 \%$ of government officials (Table 1). About $33 \%$ of consumers from business category and those working in NGO/INGOs expressed that higher price doesn't matter if the product is really organic. Various study supported that 
consumers will give second priority to the price of the products and they always look for the quality organic food. They feel that the price of organic food becomes the cost of investment in "good health" (Aryal, 2008, Menon 2008, Sandalidou et.al, 2002). Can you further elaborate why these differences among the different categories of consumers occur?

Table 1. Consumers' perception about the price of organic products for different categories ( $\mathrm{N}=30$ in each category)

\begin{tabular}{lcccc}
\hline & Reasonable & High & Not Important & No Difference \\
\hline Teachers & 14 & 6 & 7 & 3 \\
NGO/INGOs & 10 & 8 & 10 & 2 \\
Health professionals & 10 & 9 & 8 & 3 \\
Government officials & 18 & 5 & 5 & 2 \\
Business people & 10 & 6 & 11 & 3 \\
Vegetable buyers at & 9 & 15 & 3 & 3 \\
Kalimati Market & & & & \\
\hline
\end{tabular}

\section{MAJOR MARKET OUTLETS FOR ORGANIC PRODUCT MARKETING IN THE VALLEY}

Organic Village and Organic World and Fair Future (OWF) are two major organic companies dealing with organic products in the valley. Besides Baluwatar, Bakhundole, Kupandole (predominantly the domain of Organic Village), Jhonche and Basundhara (OWF's domain), there are few other market outlets for organic products. Love Green Nepal, Farmers cooperatives Gamcha, Bhatbhateeni Supermarket, Namaste Supermarket, Caroline Restaurant Mike's Breakfast, Bluebird Super market, Kathmandu Guest house, Summit Hotel and HASERA agriculture farm are also involved in marketing different forms of organic products. Organic Bistro is a restaurant where almost all the food products are organic.

\section{FACTORS AFFECTING CONSUMERS’ WILLINGNESS TO PURCHASE}

Consumers' willingness to purchase is influenced by various factors. The major factors identified by the consumers are lack of information available to consumers, higher prices over those of conventional foods, and the limited and erratic domestic supply. The majority $(88 \%)$ of the consumers reported that they are not getting regular supply of the products which makes them frustrated to go to buy again. Besides, most of the consumers $(60 \%)$ also mentioned that they do not trust the product as pure because there is no mechanism that differentiates organic from inorganic. This means there is no certified products with well label and full information. Business people reported that the organic vegetables and fruits are having less appeal. This is also supported by the study conducted by Bhatta et.al (2008). Organic products brought to market places are some time rejected by consumers due to their poor external appeal.

\section{CONSUMERS' VIEWS FOR THE PROMOTION OF ORGANIC PRODUCTS}

Increased demand of organic foods signals that willingness of the people to pay price premium for organic products is increasing. While asking the consumers what are the key areas needed to be improved for the promotion of this sector, the answer from majority of them $(89 \%)$ was that quality is the number one priority area which needs to be improved to increase the demand for organic products. The quality of the present products is not 
satisfactory though consumers are using such products mainly due to the health reasons. Similarly, about $75 \%$ of the consumers reported that there is urgent need to work on processing, packaging and labeling to inform the consumers. At present, consumers are buying the goods based on their trust with the traders and producers. In such cases, consumers have put forward their opinion for the certification of the products with authorized certification body. Ranabhat (2008) advocated that certification can help differentiate the organic products from other products, which can be helpful to promote organically grown products in the market. Information on the products including the nutritive value, origin, manufacture and expiry date as well as brand name whether it is pure organic or not are the important aspects of the product development and meantime will also encourage consumers to buy without any hesitation. The interviewed traders have same feelings about the information package on the product (Aryal 2008, Bhatta et.al. 2008).

The survey revealed that many people are not well aware about the availability of the organic products in the market. Those who are aware about this and buying from one store are also not well aware about other outlets where they can buy the products. It is therefore, necessary to disseminate and publicize the information widely so that all the people can have access to information and can make their own decision. More than half $(60 \%)$ of the surveyed consumers reported that the supply of organic products is very low and season specific. There are various cases where consumers could not get leafy vegetables as it was finished within two hours. So, there is a very good scope to go for organic farming even in off-season production.

\section{CONCLUSION AND RECOMMENDATION}

Organically grown products are available in the markets of Kathmandu valley but in limited amounts though the growing demands are there for such products. Consumers are willing to pay price premium of $5-50 \%$ for organic products which can be viewed as the cost of investment in human health. Knowledge and awareness about organic products can affect attitudes and perceptions about the product and, ultimately, buying decisions of the consumers. Vegetables followed by fruits and beans are the most preferred and highly demanded crops at present and the price of vegetables specially the leafy ones are higher than other normal vegetables. But, quality characteristics affect consumers' preferences for organic products; with the most important including health and nutritional value, taste, and fresh and general appearance. Consumers' willingness to purchase are influenced by limited and erratic supply, higher price of the products and very limited access and information.

\section{ACKNOWLEDGEMENTS}

We wish to thank all the consumers and traders who patiently shared their time, insights and views about the organic products. Special thanks are due to Ms. Elisabeth Kerkhoff, Agro-forestry Specialist of International Centre for Integrated Mountain Development (ICIMOD) for providing comments and inputs on the paper. Finally, Nepal Permaculture Group is highly acknowledged for providing financial and logistic support for this study.

\section{REFERENCES}

Aguirre, Gonzales J.A., 2001. Marketing and Consumption of Organic Products in Costa Rica. Working Paper No.5. The School for Field Studies, Centre for Sustainable Development, Atenas, Costa Rica. 
Aryal, K.P., 2008.General perceptions of producer, traders and consumers about organic products in Kathmandu valley. In P. Chaudhary; K. Aryal and D. Tharu (ed.), Proceedings of International Workshop on Opportunities and Challenges of Organic Production and Marketing in South Asia, NPG, Kathmandu, Nepal, pp.120-124.

Asadi, A., M. Akbari, A. Sharifazadeh, and S.M. Hashemi, 2009. Analysis of Factors Affecting Agricultural Organic Products Diffusion among Consumers: Perception of Extension Workers. World applied science journal. 6 (3): 331-338.

Bhatta, G.D., W. Doppler, K.B. KC, and A.Ranabhat, 2008. Potentials of Organic Agriculture in Nepal. In P. Chaudhary; K. Aryal and D. Tharu (ed.), Proceedings of International Workshop on Opportunities and Challenges of Organic Production and Marketing in South Asia, NPG, Kathmandu, Nepal, pp.34-46.

Bonti-Ankomah S.and E.K. Yiridoe, 2006. Organic and conventional food: A literature review of the economics of consumers' perceptions and preference. Final Report. Organic Agriculture Centre of Canada. Nova Scotia Agricultural College, truro, Nova Scotia, Canada.

Bourn, D. and J. Prescott, 2002. A comparison of the nutritional value, sensory qualities and food safety of organically and conventionally produced foods. Critical Reviews in Food Science and Nutrition. 42(1): 1-34.

Giannakas, K., 2002. Information asymmetries and consumption decisions in organic food product markets. Canadian Journal of Agricultural Economics. 50(2002): 35-50.

Hill, H. and F. Lynchehaun., 2002. Organic milk: Attitudes and consumption patterns. British Food Journal. 104(7): 526-542.

Krissoff, B., 1998. Emergence of U.S. organic agriculture - can we compete? American Journal of Agricultural Economics. 80(5): 1130-1133.

Makatouni, A., 2002. What motivates consumers to buy organic food in UK? Results from a qualitative study. British Food Journal. 104(3/4/5): 345-352.

Menon, M.K., 2008. Organic Agriculture and Market Potential for Organic products in India. In P. Chaudhary; K. Aryal and D. Tharu (ed.), Proceedings of International Workshop on Opportunities and Challenges of Organic Production and Marketing in South Asia, NPG, Kathmandu, Nepal, pp.87-94.

Millock, K., L.G. Hansen, M. Wier and L.M. Anderson., 2002. Willingness to Pay for Organic products: A Comparison between Survey Data and Panel Data from Denmark ,AKF Denmark.

Pokhrel, D.M. and K.P. Pant, 2008. Policy Concern in Organic Farming Promotion in Nepal. In P. Chaudhary; K. Aryal and D. Tharu (ed.), Proceedings of International Workshop on Opportunities and Challenges of Organic Production and Marketing in South Asia, NPG, Kathmandu, Nepal, pp.143-151.

Rana Bhat, B.2008. Opportunitiy and Challenges of Organic Certification System in Nepal. In P. Chaudhary; K. Aryal and D. Tharu (ed.), Proceedings of International Workshop on Opportunities and Challenges of Organic Production and Marketing in South Asia, NPG, Kathmandu, Nepal, pp.104-108.

Rodriguez, E., V. Lacaze, and B. Lupin., 2007. Willingness to pay for organic food in Argentina: Evidence from a consumer survey. Contributed paper prepared for presentation at the 105th EAAE Seminar. "International Marketing and International Trade of Quality Food Products", Bologna, Italy, March 8-10,2007.[Online]

URL: www.bean-quorum.net/EAAE/EAAE105_Program20070207.pdf

Salkind, N.J. 2003. Exploring research. Prentice Hall, Upper Saddle River, New jersey 07458

Sandalidou, E., Baourkis, G. and Siskos, Y. 2002. Customers' perspectives on the quality of organic olive oil in Greece: A satisfaction evaluation approach. British Food Journal. 104(3/4/5):391406.

Shakya, D. B., 2005. Organic Products: International Market. In G. Sharma and P.B. Thapa (ed.), Proceeding of National workshop on organic agriculture and food security, Kathmandu Nepal, pp. 145-157. 
Van Elzakker, B., N. Parrott, M. Chola Chonya and S. Adimdao (2007) Organic Farming In Africa in H. Willer and M. Yusseffi (Eds.) The World of Organic Agriculture: Statistics and Emerging Trends. Bonn, IFOAM, pp.96-106. 